Rückkehr in den eigenen Staat zu unterscheiden ist, ist gerade in den letzten Jahren in zahlreichen Verträgen westeuropäischer mit osteuropäischen Staaten bestätigt und näher ausgestaltet worden (S. 24 ff.). Sie erstreckt sich auch auf Repatriierungen als Folge von Flüchtlingsbewegungen großen Ausmaßes (S. 83 ff.). Besonderes gilt für ehemals eigene Staatsangehörige. Sie muß der frühere Heimatstaat namentlich dann zurückübernehmen, wenn die Ausbürgerung nach der Einreise in den anderen Staat erfolgt ist. Diese völkergewohnheitsrechtliche Pflicht ist Ausdruck des Grundsatzes von Treu und Glauben, der auch im Völkerrecht Geltung hat.

Vorschriften, die einen Staat zur Rückübernahme fremder Staatsangehöriger verpflichten, die sich zwischenzeitlich in diesem Staat aufgehalten haben, finden sich in den westeuropäischen Vertragspraxis seit den fünfziger Jahren recht häufig. Vor allem Beweisprobleme machen diese älteren Rückübernahmeverpflichtungen aber weitgehend ineffektiv. Neuere Verträge aus den neunziger Jahren haben die Rechtslage teilweise verbessert. Demgegenüber sind dem Völkergewohnheitsrecht entsprechende Rückübernahmeverpflichtungen noch fremd. Ausführungen zu Sonderfällen der Rückübernahme, etwa von Flüchtlingen durch den Erstasylstaat, runden das Bild ab. In einer abschließenden Bewertung mahnt Hailbronner insbesondere die Schaffung einheitlicher europäischer Standards und entsprechender Verfahrensregelungen an.

Das Werk bietet eine gründliche Bestandsaufnahme der unterschiedlichen Regelungen zur Rückübernahme eigener und fremder Staatsangehöriger. Es informiert damit über das geltende Recht und kann künftigen Regelungs- und Reformvorhaben als Grundlage dienen.

Robert Uerpmann

\title{
Brendalyn P. Ambrose \\ Democratization and the Protection of Human Rights in Africa. Problems and Prospects
}

Praeger, Westport, Connecticut / London, 1995, 219 pp., £ 46.50

Die als Consultant tätige Autorin zeichnet ein sehr düsteres Bild von den bisherigen Ergebnissen der Demokratisierung in Afrika. Sie geht in der vorliegenden Studie von der mittlerweile populären, aber nicht sehr hilfreichen Annahme aus, daß die westliche liberale Demokratie für afrikanische Staaten ungeeignet sei. Als Begründung dafür führt sie die geringe wirtschaftliche und gesellschaftliche Stratifizierung sowie die ethnische Fragmentierung, die die afrikanischen Staaten charakterisieren, an. Die in vielen Staaten seit 1990 geschaffenen demokratischen Institutionen bestünden nur auf dem Papier. Während urbane Eliten nach wie vor zahlreiche materielle und geistige Privilegien genössen, habe sich die 
Lage der armen Landbewohner kaum zum besseren verändert. Sie könnten mit den neu gewonnenen Freiheiten, wie der Pressef reiheit, nichts anfangen.

Für Ambrose bedeutet Demokratie einen Machtgewinn für die ländlichen Massen. Sie dürfe nicht auf die Städte und die dortigen Eliten beschränkt sein. Der Demokratisierung müsse eine soziale Transformation folgen, von der die arme Landbevölkerung materiell profitieren solle. Doch gerade das sei mit den Demokratisierungen, so wie sie bisher zu beobachten seien, nicht beabsichtigt. Die Autorin kommt zu dem Schluß, daß die demokratischen Transitionen bisher weder die Landbevölkerung integriert, noch deren Lebensstandard verbessert hätten. In beiden Punkten hat Ambrose zweifellos recht. Dennoch sind ihre Schlußfolgerungen problematisch, weil destruktiv. Ist es denn wirklich notwendig, daß wie die Autorin fordert - das Parlament einen sozialen Querschnitt der Bevölkerung repräsentiert, mit dem Resultat, daß fast alle Abgeordneten Subsistenzbauern sein müßten? Diese Vorstellung von Demokratie hat mit der liberalen Demokratie westlichen Zuschnitts nichts zu tun. Was ist denn problematisch daran, daß Politik von den urbanen Eliten gemacht wird? Der Hinweis, daß diese sich ihren Wählern gegenüber nicht ausreichend verpflichtet fühlen könnten, ist so nicht legitim, denn ein Abgeordneter hat sich den Wählern in Wahlen zu stellen und kann abgewählt werden. Die Gefahr, daß ein Subsistenzbauer als Parlamentarier seine eigenen Taschen füllt, ist indes nicht weniger gering.

Der Autorin ist beizupflichten, wenn sie konstatiert, daß die Verfassungsgebung ohne die aktive Mitwirkung der Landbewohner stattfindet, da diese größtenteils nicht alphabetisiert sind und, da sie in großer Armut leben, wenig oder kein Interesse am politischen Geschehen haben und keinen Input zum demokratischen System leisten können. Ihre Schlußfolgerung, "people at the grassroots must receive literacy training. Basic infrastructure must be provided, not as a result of being a 'good boy', but as the end-product of democracy. Only an enlightened and empowered popular movement will articulate such demands" (S. 22) mag sicher richtig und für die Konsolidierung eines demokratischen Systems hilfreich sein. Auf die wirklich bedeutende Frage geht die Autorin indes nicht ein: Was soll in der Zwischenzeit geschehen? Es ist kaum davon auszugehen, daß sich die ländlichen Massen in absehbarer Zukunft politisch engagieren und eine wichtige Rolle auf der politischen Bühne afrikanischer Staaten spielen werden. Im Gegensatz zur der Autorin gehe ich davon aus, daß auch ohne die Integration der Landbevölkerung eine erfolgreiche Demokratisierung möglich ist, denn die Politik wird in der Hauptstadt und dort von den Eliten gemacht. Die Gefahren, die einer jungen und fragilen demokratischen Ordnung drohen, gehen meistens nicht von der-Landbevölkerung aus, sondern vom Militär und von autoritären Tendenzen in der demokratisch gewählten Regierung. Ambrose moniert, daß der Demokratisierungsprozeß von Eliten ausgegangen ist, die Landbewohner aber von demokratischen Werten keine Vorstellung hätten. Das mag so sein, aber es wäre naiv zu glauben, daß es dazu eine Alternative gegeben hätte. Die Entwicklungsdiktaturen und die Einparteiensysteme sozialistischer oder afrikanischer Provenienz haben allesamt in den letzten drei Dekaden in Afrika versagt. 
Die Autorin geht auch der Frage nach, ob die Menschenrechte unter einem demokratischen System besser gewahrt werden als unter den autoritären Regimen. Sie legt eine Bestandsaufnahme über die für Afrika relevanten Menschenrechtschartas und -abkommen vor und stellt die große Diskrepanz zwischen den völkerrechtlichen Vereinbarungen und der Realität dar. Für Ambrose reicht es nicht aus, daß Menschen nicht ermordet, nicht gefoltert oder nicht ohne Anklageerhebung inhaftiert werden. Vielmehr müsse in staatlichen Institutionen (Polizei, Armee) und vor allem auch in der breiten Bevölkerung ein Bewußtsein für Menschenrechte geschaffen werden.

In der Tat sind einige demokratische Experimente mehr oder weniger als gescheitert zu beurteilen (Zambia, Kenya), aber es gibt auch erfreuliche Gegenbeispiele, auf die die Autorin nicht eingeht (z.B. Malawi, Benin). Würde man ihren Anspruch teilen, daß "the process of change must begin with the grassroots peasants and others in the villages throughout Africa. This group of people must be conscientized to demand from their community leaders the services for which they pay taxes" (S. 171), müßte man auf die Einführung demokratischer Systeme in Afrika noch lange warten. Davon abgesehen übersieht Ambrose, daß gerade die Kleinbauern meistens keine Steuem zahlen.

Nach der katastrophalen Leistungsbilanz der autoritären Regime in Afrika bleibt uns die Autorin die Alternative zur Einführung eines von den urbanen Eliten getragenen demokratischen Systems, das zugegebenermaßen bisher fast nirgends befriedigend funktioniert, schuldig. Ist es denn nicht schon ein Vorteil, daß politische Morde und Folter in den meisten Staaten kaum oder gar nicht mehr vorkommen, daß die Pressefreiheit und das Recht auf freie Meinungsäußerung respektiert werden und die Gründung politischer Parteien möglich ist?

Heiko Meinhardt

\section{Lorenz Müller}

Islam und Menschenrechte. Sunnitische Muslime zwischen Islamismus, Säkularismus und Modernismus

Mitteilungen des Deutschen Orient-Instituts Nr. 54

Deutsches Orient-Institut, Hamburg, 1996, 361 S., DM 56,--

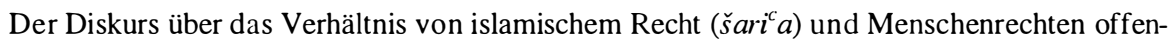
bart wie kaum ein anderer Bereich des Rechts in Nordafrika und im Vorderen Orient eine Vielzahl von Mißverständnissen, Vorurteilen und Verzerrungen. In den letzten Jahren wurden viele Darstellungen zum Thema Menschenrechte in der islamischen Welt veröffentlicht, nur selten jedoch gehen diese über Momentaufnahmen und Einzelstudien hinaus. Insofern verdient die vorgelegte Arbeit eine besondere Beachtung. Gleichsam demonstriert der Verfasser Bescheidenheit, wenn er einschränkt, "daß die ausgewerteten Stellungnahmen nur exemplari- 